\title{
Understanding of high-achieving science students on the nature of science
}

\author{
Ora Kahana* and Tali Tal
}

\begin{abstract}
Background: Although teaching nature of science (NOS) has been continually emphasized in many major reform efforts in science education, researchers claim that students do not possess adequate views of NOS. Insufficient understanding of NOS can be associated with the ineffectiveness of curricular or instructional approaches. Consequently, researchers have begun to examine ways to improve students' understanding of NOS. In this study, we purposely focused on honored students who major in the sciences to see whether extended science programs develop better understanding of NOS. We aimed to understand the relationship between science instruction and students' NOS understanding in Israeli science advanced placement courses.

Semi-structured interviews with science teachers provided data about the instruction of science in general, and NOS instruction in particular. An open-ended questionnaire that dealt with global climate change assessed students' understanding of NOS.

Results: Teachers reported about limited and implicit instruction about NOS. Although teachers believed that teaching NOS is important, the need for their students to succeed in the high-stake matriculation exams and the fact that these exams do not include questions dealing with NOS were indicated as the main reasons for the teachers' reluctance to teach NOS. Nevertheless, we found a small overall improvement in students' understanding of NOS. Two possible factors probably contributed to students' improved understanding of NOS: conducting inquiry projects and teaching cases in history of science. Yet, in both contexts, the understanding improved only in one aspect of NOS.

Conclusions: The small improvement in understanding NOS reflects the limited and non-systematic teaching of NOS. Implicit instruction is not effective enough to promote understanding of NOS, even in advanced 2-year science program, where both students and teachers are highly capable. Other factors that could explain the little improvement are insufficient subjects in the curriculum that emphasize NOS and teaching methods that do not encourage discussion about NOS.
\end{abstract}

Keywords: Nature of science; Scientific literacy; High school; Socio-scientific issue; Science curriculum

\section{Background}

Citizens in Western societies are confronted daily with the need to understand science-based social issues, such as genetically modified foods, stem cell research, global climate change, and nuclear energy. To take part in discussing such issues, one needs to understand core scientific ideas as well as be able to understand how scientists work and know scientific practices (NRC National Research Council 2012). In recent decades, this understanding is referred to as the nature of science

* Correspondence: oraka@technion.ac.il

Department of Education in Science and Technology, Technion, Haifa 3200003, Israel
(NOS). NOS refers to 'the epistemology and sociology of science, science as a way of knowing, or the values and beliefs inherent to scientific knowledge and its development' (Lederman 1992). Within the NOS education research area, Lederman's operational definition of NOS is widely used.

Developing an understanding about NOS is a valuable aspect of scientific literacy that could allow students to make informed decisions and act responsibly as adults when faced with complex issues related to science (Allchin 2011; Khishfe 2012; Sadler et al. 2004; Zeidler et al. 2002). Teaching NOS has been continually advocated in many major reforms of science education. As stated in

\section{至}


the K-12 Framework for Science Education, for example, 'although there is no universal agreement about teaching the nature of science, there is a strong consensus about characteristics of the scientific enterprise that should be understood by an educated citizen' (NRC National Research Council 2012, p. 77). In the chapter 'Suggestions of Fields or Topics to be Included' the framework states that many of those who provided comments to the framework thought that the nature of science needed to be made an explicit topic or idea. They noted that the NOS does not emerge simply through engaging with practices. Similarly, the Israeli national science curricula for the high school include few teaching goals related to NOS as well (Israel Ministry of Education 2010, 2011a, 2011b, in Hebrew).

Since the late 1980s, much research has been conducted on students' NOS understanding and practices that effectively help them develop more accurate understanding of scientific practices and knowledge construction. Although teaching NOS has been continuously advocated, research shows that high school students do not possess 'adequate' views of NOS (Dogan and Abd-El-Khalick 2008; Khishfe 2012; Lederman and O'Malley 1990). Many science teachers hold naive beliefs about NOS and hold inadequate understanding, knowledge, and skills needed to teach science in ways consistent with science education reform goals (Akerson and Hanuscin 2007; Lederman 2007). The literature clearly suggests that even when possessing an accurate understanding of NOS, science teachers often do not consider it an important educational objective and therefore do not explicitly teach it (Abd-El-Khalick et al. 1998; Bell et al. 1998). These studies suggest that accurate and effective teaching of NOS remains an elusive goal in science education.

Two general approaches have been highlighted to enhance students' understanding of NOS, the implicit and the explicit. The implicit instruction suggests that by 'doing science', students will come to understand NOS with no further specific reflection on NOS. Various studies have shown little impact of the implicit approach (Bell et al. 2003, 2011; Khishfe and Abd-El-Khalick 2002; Meichtry 1992; Sandoval and Morrison 2003; Schwartz et al. 2004). On the other hand, much research has been published that suggests that NOS understanding is developed with explicit instruction coupled with ample opportunities for reflection (e.g., Abd-El-Khalick and Lederman 2000a, 2000b; Akerson and Volrich 2006; Aydeniz et al. 2011; Khishfe and Abd-El-Khalick 2002; Rudge et al. 2014). Explicit/reflective NOS instruction, according to Abd-El-Khalick and Lederman (2000b), involves discussions that emphasize the specific tenets of NOS and often historical examples of how scientific knowledge was garnered.

Promoting deep and robust NOS understanding also demands that instruction occurs in a variety of contexts.
Contextualized activities allow explicit and reflective teaching of NOS (e.g., Clough 2006; Duschl 2000; Sadler et al. 2010; Schwartz et al. 2004). The literature points to three main approaches for contextualizing NOS.

One approach is engaging students in various forms of scientific inquiry (Bell 2007; Crawford 2012; Duschl and Grandy 2008). The aim of student-based inquiry is to make the learning resemble authentic investigative scientific processes. Through inquiry activities, students may learn how scientific claims are constructed. But the student inquiry seems critically incomplete. The simple problems presented in school settings may not be the basis of understanding NOS. Students do not automatically transfer lessons from their own activities to real-life contexts (Clough 2006; Sandoval and Morrison 2003). In addition, NOS understanding is limited to what a student can achieve in a school setting, which could be far away from the processes relevant to citizen decision making. There are contexts of science that cannot be easily modeled in the classroom, for example, cultural biases, economics, and conflicts of interest and credibility.

A second form of contextualizing NOS is through teaching historical cases, which the research community is divided with respect to its effectiveness (Irwin 2000; Lin and Chen 2002; Abd-El-Khalick and Lederman 2000b).

The third approach is of teaching relevant and contemporary cases (Allchin 2011, 2014; Osborne et al. 2003). Various studies support the use of socio-scientific issues (SSIs) in NOS instruction. SSI-learning environments incorporate processes that relate to NOS and provide numerous opportunities for explicit connections to aspects of NOS. Those studies found that SSIs were effective contexts for improving students' NOS understanding (Bell et al. 2011; Eastwood et al. 2012; Khishfe and Lederman 2006; Lewis et al. 2006). Not always, teaching SSI has a positive effect on the development of NOS understanding. When SSIs are presented in generic and narrow way, they tend to be decontextualized and ineffective. Another possible limitation that several researchers found is that students focus selectively on the scientific evidence and other aspects that support their own views and values. They do not examine all the available evidence in a more complete or balanced way (Sadler et al. 2004; Zeidler et al. 2002). Such tendencies might undermine efforts to teach how science works or even to show how judgments in science may be biased by prior beliefs.

The main body of research on students' understanding of NOS comes from the United States (US). In Israel, where this study took place, there is little research on students' understanding of NOS. Since the work of Tamir (1972) who studied the impact of the 1960s science curricula on the understanding of science processes by high school students, not much has been done. Although Tamir found that lab investigations were central 
across the science curriculum, NOS was only implicitly mentioned as part of the lab protocol. Two decades later, Tamir (1994) studied the development of views about science among 14-17 year old students and found only naive views in all grade levels. No recent study was carried out in Israel on students' views of the NOS. Thus, in this study, we investigated NOS understanding of high-achieving Israeli students enrolled to advanced science courses.

Most studies reported in the literature examined the effect of a single intervention that usually lasts several weeks or a few months. In addition, examining the effect of the intervention on the understanding of NOS was done immediately after the intervention. Taking a different approach, we focused on the entire 2-year program in the sciences and examined NOS understanding of students enrolled in high-level science courses.

The research questions we followed were:

1. How and to what extent NOS is taught in Israeli high-level science courses?

2. What is the relationship between enrollment in high-level science courses and students' NOS understanding?

In the remainder of this paper, we describe the assessment instrument that we designed specifically to measure the student understanding of NOS. We characterize the NOS instruction in advanced science courses and we present the results of the changes in students' NOS understanding.

\section{Methods}

The mixed methods approach was used for data collection and analysis in this study. We adopted the pragmatic approach of Morgan (2007) and the justifications for combining quantitative and qualitative approaches by Johnson and Onwuegbuzie (2004). Johnson and Onwuegbuzie outline a continuum of mixed method research that spans from quantitative dominant to qualitative dominant. We place our research at the middle of this sequence. Our main data came from open-ended responses and interviews, but we analyzed the data using categories that are based on the research literature. With this respect, we agree with Krippendorff (2004) who argued that the distinction between qualitative and quantitative content analysis is not relevant anymore. Basically, mixed methods provided a comprehensive response to the research questions that are of different types. We content analyzed the interview data and the written texts, and we carried out statistical analysis to investigate the relationships we were interested with.

\section{Context}

In most countries, all students are required to take some science courses to graduate high school. In Israel, however, students elect major topics in the high school. High-level elective courses are equivalent to Advanced Placement (AP) courses in the US and Canada. Thus, students in Israel either enroll in science courses in one or two fields (biology, physics, chemistry) or can decline from studying science at all in the upper classes. In grades 11 and 12 (age 16 to 18), Israeli students are prepared for the matriculation exams. Matriculation exam diploma is a basic requirement for higher education studies application, and high-quality diploma is required for consideration by competitive programs.

\section{Participants}

Altogether, students from 11 urban and countryside high schools that serve different socioeconomic groups participated in the study. The schools were chosen based on an initial telephone conversation with a science teacher, getting the teachers' consent and the approval of the principal. Altogether, 325 students (152 males and 173 females) took both the pre-test (in early 11 th grade) and the post-test (in late 12th grade).

All the students majored in the sciences in the high level: 82 biology majors, 81 chemistry majors; and 81 physics majors. We included a comparison group of 80 students who majored in a non-science topic (i.e., history, literature, geography, mass communication, fine arts, etc.). Due to the mandatory national curriculum in Israel, it was reasonable to assume that the students' background in science in terms of the curriculum they studied was similar prior to beginning the high-level courses in 11th grade.

In addition, 16 teachers who taught the science classes who participated in the study were interviewed. As shown in Table 1, all the teachers were highly experienced (24 years on average). They all had advanced degrees in the science disciplines.

\section{Instrument and data collection NOS teaching}

Semi-structured interviews with the teachers provided data about the instruction of NOS. The teachers were asked to tell about their practice in class in general and with respect to NOS in particular. All the interviews were audio-taped and transcribed.

Prior research has shown a relationship between teachers' NOS understanding and their teaching of it. When science teachers hold naive beliefs about NOS, it is rarely addressed in an accurate and effective manner (Lederman 2007). Teachers that hold naive views of NOS might face challenges in developing their students' own understanding of it. To avoid such impact, we assessed the teachers' NOS understanding prior to the study. The NOS understanding of the science teachers was determined using the Views of Nature of Science questionnaire (VNOS-C), (Lederman et al. 2002). This questionnaire had previously been used 
Table 1 The participating teachers $(N=16)$

\begin{tabular}{ll}
\hline & Number \\
\hline Field & 5 \\
Biology & 6 \\
Chemistry & 5 \\
Physics & \\
Experience (years) & 3 \\
8 to 18 & 8 \\
19 to 29 & 5 \\
30 to 40 & \\
Degree & \\
Masters & \\
Biology & 4 \\
Chemistry & 5 \\
Physics & 3 \\
PhD & \\
Biology & \\
Chemistry & \\
Physics & 1 \\
\hline
\end{tabular}

and was widely validated (Abd-El-Khalick 2005; Lederman et al. 2002; Schwartz et al. 2004). We found that the teachers' views of NOS were informed in all the aspects, which allowed us to rule out any concerns about teachers' understanding of NOS.

\section{Students' NOS understanding}

In this quasi-experimental study, we looked at the extent to which NOS understanding changes after students enroll in high-level science courses. The questionnaire was administered to 325 students at the onset of the major program and at the outset of the program.

An open-ended questionnaire in the form of a SSI assessed students' understanding of NOS. Many studies have recommended that a better way to assess understanding of the nature of scientific enterprise would be through analyzing evaluative thinking of learners in authentic situations where the complex linkage between science and society could be exposed. Various studies suggested that personal understanding of the NOS and preferences towards scientific information mediate scientific thinking. Therefore, the assessment is based on recommendations to use SSIs as an assessment method in science in general (Tal and Kedmi 2006; Tal et al. 2011) and for assessing students' understanding of NOS in particular (Sadler et al. 2004; Wu and Tsai 2011; Yang 2005). In developing the instrument, we addressed a current case, as a typical citizen might encounter in the news media. The task required wellinformed analysis of NOS as advocated by Allchin (2011). The students were provided with two conflicting reports on climate change reflecting different interpretations of one of two groups of researchers, and both reflected the public discourse about the relationship between society and science. In choosing the topic, we were influenced by the worldwide discussion of climate change, which is heavily discussed in Israel as well. As in most other countries, the vast majority of Israeli scientists agree with the IPCC Fifth Assessment Report about anthropogenic contribution to climate change, with a small minority that argues that climate changes are the result of natural processes. The open-ended questions that followed the scientific information required the students to understand the NOS knowledge in the context of the climate change debate. The issue of global climate change lends itself to discussion of data use and interpretation, cultural influence on the progress of science, and the evolution and inconsistency of some scientific ideas. Additionally, this particular issue was selected because it does not require technical knowledge or subject-related knowledge in order to comprehend and analyze the issue. Furthermore, the authors agreed that this issue was pedagogically appropriate for the student grade levels (11th and 12th).

The instrument was piloted with 80 high school students at the beginning of their major subject studies. After feedback from the students and their teachers, we shortened the text of the articles and reduced the number of questions from 13 to 8 to fit a 45 -min class period. Although the smaller number of questions could reduce the reliability of the questionnaire, we acknowledged the teachers' recommendation that it is important that students read carefully the texts and answer each question in-depth. In addition, a few questions were rewritten to improve clarity.

The revised version was given to six high school science teachers, four of whom are science education researchers as well, and to two faculty members in science education. They examined the questions to establish their content validity. Furthermore, the panel agreed that the questions were appropriate for the student grade levels (11th and 12th). The panel had further suggestions which were introduced in the final version.

For the instrument to have construct validity, we used the 'known groups validation' design. If a test is valid, then test scores must discriminate across groups that are theoretically expected to be different on the trait measured. A group of respondents, which was composed of seven individuals with advanced degrees in science education or in science, completed the questionnaire. Individuals in these fields may reasonably be expected to have developed NOS understanding. Seven other individuals were selected as non-expert group. They had comparable educational backgrounds in term of years and degrees, but in nonscience fields, making them less likely to have contemplated issues related to NOS. Each participant completed the questionnaire. Data analysis indicated that the expert 
group's responses reflected current NOS understandings at a rate three times higher than those of the non-expert group (33 informed answers compared to 11 informed answers). These results supported the construct validity of the instrument. Finally, it was deemed satisfactory by the Chief Scientist of the Ministry of Education, whose approval is required for any research carried out in schools in Israel.

In the final version of the questionnaire, the students were asked to provide written responses to the following five questions:

1. Explain how, based on the same data, researchers came to different conclusions about the cause of global climate change.

2. Is it possible to determine which group is right? Explain your answer.

3. Is one of the documents more scientifically sound than the other? Explain your answer.

4. Is it possible that the researchers of group A or B will change their conclusions? Explain your answer.

5. Could non-scientific factors (e.g., social, religious, political, or economic) affect scientific research? Explain your answer and provide examples. Use these documents and other personal knowledge.

The questions assessed students' conceptions relating to the following areas of the nature of science:

a. Scientific knowledge is interpretive; the same evidence can be differently interpreted (question 1).

b. Scientific knowledge is limited (question 2).

c. Scientific knowledge is founded on empirical evidence yielded by observations or controlled experiments (question 3).

d. Scientific knowledge is tentative and subject to change (question 4).

e. Scientific knowledge is subjective and influenced by non-scientific factors like social and economic (question 5).

These aspects have been previously used to assess student understanding of the NOS (Khishfe 2012; Khishfe and Lederman 2006, 2007; Koksal et al. 2013; Lederman et al. 2002; Sadler et al. 2004). The authors agreed that these particular NOS questions were closely related to the socio-scientific topic of climate change.

The questionnaire was administered twice: at the onset of the major program, at the beginning of 11th grade and at the outset of the program, at the end of 12th grade.

The analysis of three other questions that assessed the ability to distinguish between evidence and interpretation is not in the scope of this article.

\section{Data analysis}

The teacher interview data were inductively analyzed to identify themes and construct categories. Several cycles of analysis were applied by the first author to retrieve all information. Subsequently, the categories were organized as patterns.

In order to assess students' views about NOS, content analysis was performed in several stages on students' responses to the five open questions. The qualitative data analysis is interpretive in nature and focused on the meanings that participants gave to the aspects of NOS. Specifically, each participant was rated as 'informed' (for understanding NOS) or 'uninformed' (for not understanding NOS) based on the consensus views about the NOS described in NOS literature (Abd-El-Khalick 2012; Eflin et al. 1999; Lederman et al. 2002; McComas et al. 1998; Smith et al. 1997). The answer sheets of 50 students were randomly pulled out and analyzed by the first author. This analysis provided a range of profiles that enabled identification of patterns of informed views. In Table 2, we present the students' answers that express informed views about the five aspects.

The analysis was then reconfirmed by a group of five science education researchers, two of whom were high school teachers as well. Afterwards, the rest of the questionnaires were analyzed by the first author, and in the case of vague answers, the two authors discussed each response until reaching an agreement. Finally, we were left with 38 responses on which we could not agree. These were given to three graduate students in science education who analyzed them individually. Their initial agreement was $78 \%$, and after further group discussion with the authors, their agreement exceeded $92 \%$.

To avoid possible bias, analysis was done by item rather than by answering sheet, meaning that first, question 1 was analyzed across all answer sheets, then question 2, and so forth. In addition, the questionnaires were marked only with a number code to avoid identification.

The relationship between science studies and students' NOS views was investigated by comparing the views of science students to the views of students who did not major in science. By comparing changes in students' views of NOS with respect to their science advanced courses, we could point to possible factors in the science instruction that could affect students' NOS views.

\section{Results}

\section{Limited NOS instruction}

In the interviews, teachers of the science classes who participated in the study described their instruction about NOS.

From the answers to the question 'Did you teach about NOS?', we learned about the limited and non-systematic instruction of NOS. Teachers recognized the merits of 
Table 2 Students' informed views in five NOS aspects

\begin{tabular}{ll}
\hline Aspect & The answer \\
\hline Interpretive & $\begin{array}{l}\text { People's conclusions stem from ways of thinking and interpreting facts. Because of different ways of thinking and beliefs, } \\
\text { conclusions could be different despite the same data. } \\
\text { Limited }\end{array}$ \\
& $\begin{array}{l}\text { It is impossible to determine who is right because there are not enough data or proof to support or refute the different } \\
\text { scientists' theories. } \\
\text { It might be possible if further research will be carried out and if more data will be accumulated to support or falsify the current } \\
\text { conclusions of one group. } \\
\text { No document is more scientific. They both show scientific facts that prove their opinions. } \\
\text { The document that includes more facts is more scientific. } \\
\text { Researchers of one group can change their minds if they are convinced by the other group that its argument is true or if new } \\
\text { discoveries appear that support the other argument. } \\
\text { Other factors can influence scientific research. An example from the past is the church's objection to Galileo's theory that Earth } \\
\text { orbits the sun. A current example is the way interest groups support studies on global climate change, or radiation from cellular } \\
\text { phone antennas, when these studies are in line with their interests. }\end{array}$ \\
\hline
\end{tabular}

NOS lessons in developing scientific literacy, but lack of time and the need to prepare the students for the national exams prevent them from teaching it:

Although I think that teaching NOS is important, I taught little and on rare occasions. The limited time I had was dedicated to preparing my students for the matriculation exams (Tami).

I would like to dedicate much more time (to teach NOS) but it's impossible in terms of the limited hours I have. I prepared the students for the matriculation exams, and the exams do not include questions about NOS (Adi).

NOS is very important to me. I want students to develop thinking skills that they can use outside of science class. But the matriculation exam assesses factual knowledge, so I really taught very little about NOS (Yael).

It appeared that the teachers are concerned about anything that might undermine their students' test results. We found that teachers refrained from dealing with the idea that scientific knowledge has a degree of tentativeness and is influenced by interpretation because they did not want the students to be uncertain of what they need to write in the exam.

I do not teach about different interpretations in science or that science is changing. I teach scientific facts that explain the process. I do not want to give students additional information that will confuse them in the matriculation exam (Leah).

When the teachers were asked to describe a context in which they taught NOS, they all said that they never dedicated special time for it. They taught NOS on different occasions and in different contexts. The contexts varied depending on the scientific discipline. Physics teachers, for example, taught NOS in the context of the history of science:

I teach eleventh grade mechanics. Mechanics is a very clear and well established subject; very

understandable. But modern physics is different; it has contemporary things: we talk about the research questions, different views, and that it is still unclear who is right (Zehava).

To teach about the changes that occur in theories, I present quantum mechanics versus Newtonian mechanics. I present the problem of the photoelectric effect and the development of scientific knowledge. I show them Einstein's proposed solution to the problem. The wave model of light could not explain this phenomenon. I emphasize that we are learning theories and models that may change (Benny).

Chemistry teachers indicated that the history of science is not in the curriculum, and biology teachers indicated that evolution is the only topic that has some historical elements:

Yes, there is only one relevant topic in the curriculum for teaching NOS - evolution, but it is not a compulsory subject and I did not choose it (Rachel).

The biology and chemistry teachers indicated that the main context for teaching about NOS was the laboratory work. Although they do not explicitly teach NOS, they believe that engagement in inquiry help students to develop an enhanced understanding of aspects of NOS, such as the empirical nature of scientific knowledge, which is specifically emphasized and practiced during engagement in inquiry-based laboratory learning. 
Biology teachers mentioned the compulsory inquiry project as the context contributing the most to understanding NOS. High school biology students who take the matriculation examination carry out an inquiry project which accounts for $20 \%$ of the exam. The project, which is an open inquiry, begins by identifying phenomena in the field and continues either on site or in the lab. Working in teams of up to three, the students are expected to function autonomously from the stage of identifying the phenomenon to raising inquiry questions, collecting and analyzing data, whereas the teacher functions as a mentor, directing and focusing the learning throughout the entire process. The open-inquiry project spans 6 to 12 months. Biology teachers' responses indicated a great appreciation for the contribution of the inquiry project to understanding NOS:

The inquiry project contributes a lot. It's the highlight of biology studies. I am only guiding and leading, rather than explaining things. I encourage thinking. The students have difficulties drawing conclusions and interpreting their findings, but it is instructive. The students are exposed to different interpretations of their group findings. I don't teach NOS and we don't discuss it, but from what I see of the students during the process, their scientific thinking develops through the inquiry project (Leah).

In the inquiry project, the main difficulty for students is to understand the relationship between evidence, interpretation, and conclusions. At the beginning of the projects, most of them were not able to make the difference between results and conclusions, or between evidence and interpretation. I see it when students write the conclusions. They do not know what to write. They repeat the results, and say these are the conclusions. At the end of the project, most of the students get it (Hana).

The participating physics teachers indicated that physics labs are confirmatory laboratories, so they do not develop scientific thinking and NOS understanding. Much of the 'inquiry' that occurs in their curriculum is limited to verification of what other scientists have found, instead of guiding students towards a greater understanding of scientific epistemologies.

Another context for teaching NOS mentioned by the teachers was discussing topics presented in the media:

When the media brings interesting topics, we discuss them in class. Recently, we talked about the politics of diseases and drugs. Do pharmaceutical companies aim at saving the world? If a teacher does not say explicitly, the students do not know. The curriculum does not require teaching it but it's important to me. It depends on how the teacher teaches it, and in what context. It is important to incorporate these issues even if it is not directly related to the curriculum (Neta).

Students bring to the class newspaper advertisements. I tell them to be critical: 'Who wrote it? Why? 'Look at the facts and do not rush to conclusions'. I emphasize the importance of factual basis (Ilana).

More current events teachers mentioned were the Nobel Prizes awarded to Israeli scientists. Dr. Dan Shechtman received the Nobel Prize for chemistry during the study. All teachers indicated that they referred to it, mainly because his discovery was incidental at first and was then rejected by the scientific community for years until it was accepted and then appreciated. Teachers did not use this opportunity to teach various aspects like tentativeness, limited nature, interpretive nature, and the subjective nature of scientific knowledge:

I teach very little NOS. This was discussed a few months ago when Professor Dan Shechtman was awarded the Nobel Prize. First of all, I discussed it because of Israeli pride. I talked about the persistence of the researcher, the obstacles along the way, and the resistance of scientists to accept a new theory. Everyone thought he was imagining it. There was no such thing as pentagonal symmetry - it cannot be. I told them the greatest scientists did not believe him and mocked him, and he insisted on the facts (Miriam).

When Professor Shechtman won the Nobel Prize I led a discussion in the class. I talked about the social aspect: the scientific community did not believe him, the difficulty of scientists in adopting new theories that contradict the old ones. Now all opponents have to change their perception about the structure of crystals (Ronit).

It seems that teachers did not take advantage of opportunities to teach different aspects of NOS. When the first author demonstrated how they could have taught different aspects of NOS in the contexts they referred to in the interviews, they acknowledged that they did not think about it and they will try to do it:

You're right. I wish there was more guidance for teachers on how to do it and in what contexts. I'll try to do it next year (Neta).

It is a good idea. I think it is very important to integrate various aspects of the NOS. If it is not time consuming, I will try to teach it on different occasions (Yael). 
The teachers were asked to describe the teaching methods they implement in class. Most of the teachers said they usually apply didactic teaching in order to save time. They have to teach many topics in a limited time, and by lecturing they can do it effectively:

I usually teach by lecturing. I was keen to lead open discussions with my students, but felt I lacked the necessary hours to do so. When I did make use of classroom discussion, it was the questions-and-answers type, my questions and students' answers, and not a dialogic discussion (Avi).

Another reason that NOS instruction was given by lectures is that the teachers, and especially physics teachers, regarded the content to be taught as truths about nature that must be conveyed to their students as a collection of facts without different opinions. As the teachers described, they had an orientation towards making their lessons run smoothly and according to the lesson plan.

\section{Changes in students' NOS views}

To answer research question 2, we compared students' views prior to and at the end of their major program in the sciences and in non-science fields. Using the McNemar Test, we compared the distribution of informed and uninformed NOS views by students' major. The distribution of informed and uninformed NOS views in five aspects by major field is shown in Figures 1, 2, 3, 4, 5.

In the interpretive aspect of scientific knowledge (Figure 1), we found a significant increase $(16 \%, p<.05)$ in the informed views of biology students. In other groups, there was a small and non-significant increase.

As Figure 2 shows, the percentage of students with informed views did not change significantly in any of the groups.
Similarly, there was no significant change in the views of students of the empirical aspect of scientific knowledge (Figure 3).

In the tentative nature of scientific knowledge aspect, the number of informed views of physics students increased significantly $(18 \%, p<.05)$. In the other fields, the increase was not significant (Figure 4).

Finally, all the groups improved their understanding of the social influence on the nature of science, but this improvement was not significant (Figure 5).

In comparing the students' NOS views by their major subject in science, we found that, in general, science students outperformed their non-science majors in all aspects. In looking more closely at science majors, we found only one aspect in which biology students improved significantly, which is understanding the interpretive nature of scientific knowledge, and one aspect in which physics students improved significantly, which is understanding the tentative nature of scientific knowledge.

\section{Discussion \\ NOS instruction is limited and rare}

Despite policy documents produced by the Israel Ministry of Education (2010, 2011a, 2011b, in Hebrew) that have raised the importance of teaching NOS, we found limited improvement in the understanding of NOS among all students after 2 years of high-level science courses. This may reflect a large gap between the rhetoric of policy and classroom practice. There is consensus among science education researchers that most high school science teachers neither know how to teach NOS effectively nor do they pay enough attention to the teaching of NOS (Lederman 2007). Even though teachers in this study had adequate understanding of NOS, this was not necessarily translated into their classroom practice. As Abd-El-Khalik et al. have pointed out, knowledge of NOS is a necessary condition for teaching NOS, but it is not a sufficient

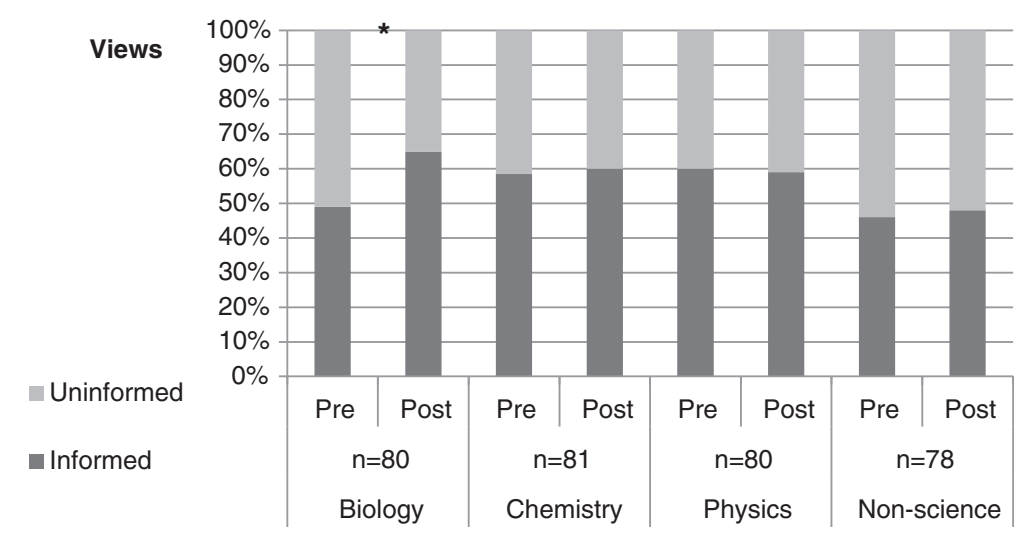

Figure 1 Understanding the interpretive nature of scientific knowledge. ${ }^{*} p<.05$ 


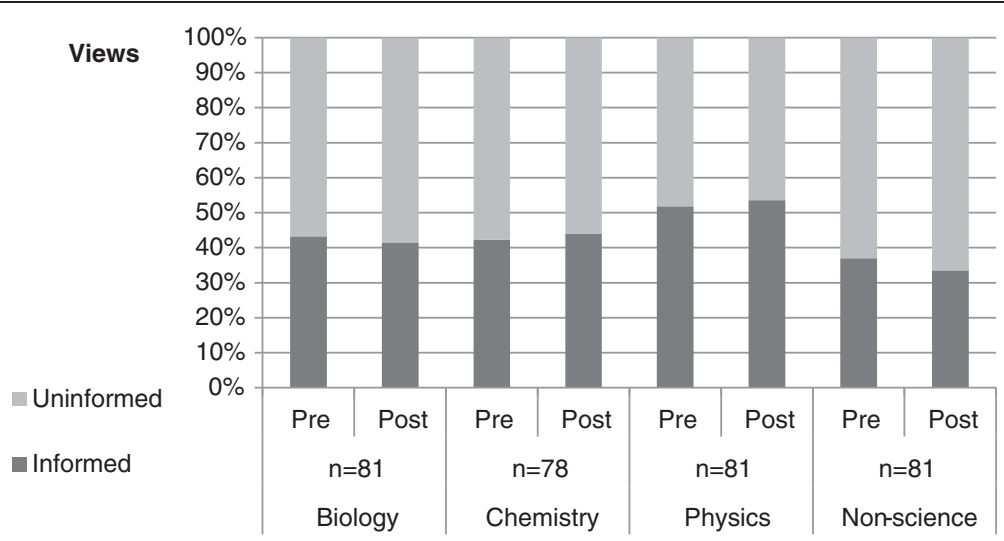

Figure 2 Understanding the limited nature of scientific knowledge.

condition (Abd-El-Khalick et al. 1998; Abd-El-Khalick and Lederman 2000a).

Although teachers involved in this study believed that teaching NOS is important, their teaching of NOS was limited and sporadic. The need for the students to succeed in the matriculation exams and the fact that the exams do not include NOS questions were indicated as the main reason for the teachers' reluctance to teach NOS. In Israeli high schools, the last 2 years are geared to preparing students for the matriculation exams that assess students' knowledge on subjects studied in high school. Their scores have great implications for the individual's future. Acceptance to elite universities is heavily influenced by the exams scores. While the formal goals of the various curricula promote the teaching of NOS, the exams do not truly reflect it. Teachers felt they needed to focus on developing the knowledge and skills that will have the greatest impact on their students' scores. They even refrained from dealing with the idea that scientific knowledge has a degree of tentativeness and is influenced by interpretation because they did not want the students doubt what they needed to respond in the exam.

Another factor that could explain the limited instruction of NOS that we found is the limited number of opportunities provided in the curriculum that emphasizes NOS.

\section{Teaching strategies}

In addition to the limited instruction of NOS indicated by the teachers, we suggest that traditional teaching strategies could explain the small improvement in NOS understanding. The interview data indicated that didactic teaching was the most prevalent among the participating teachers. Rote learning is common, and scientific ideas are often presented as 'inherited facts' without providing enough opportunities for students to develop deeper insights into the reasons for regarding a scientific assumption to be true. When teachers use classroom discussions, they are more of a question-and-answer type than a dialogic discussion. As the teachers explained, this is the only way they can cover all the content required in

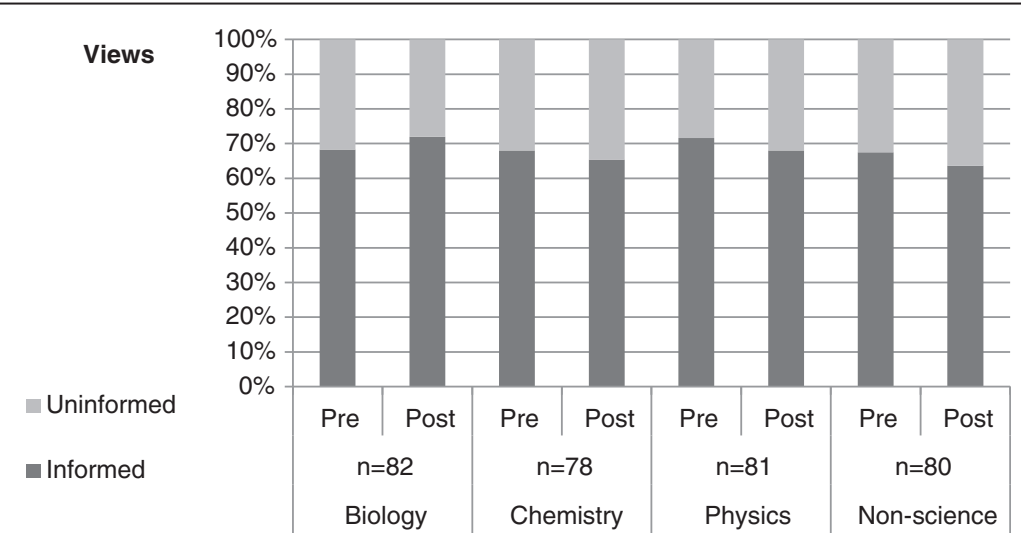

Figure 3 Understanding the empirical nature of scientific knowledge. 


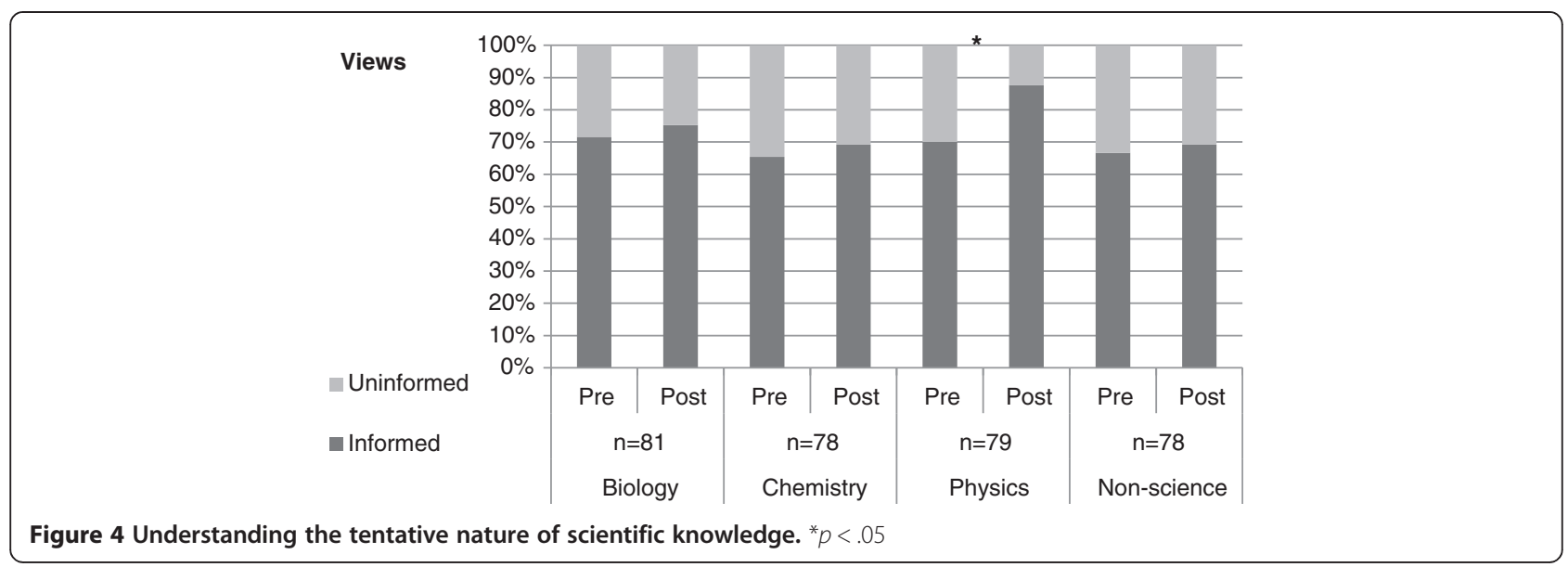

the matriculation exams. The limited discussions prevent students from deeper thinking and reflecting on what they have done.

The literature has shown that explicitness, reflection, and embedding are important activities in changing NOS understanding (Khishfe and Abd-El-Khalick 2002; Khishfe and Lederman 2006, 2007; Koksal et al. 2013). The findings of those studies suggest that effective teaching of NOS requires establishing a context in which it is possible for students to engage in reflexive epistemic dialogue. Didactic teaching does not allow this, which could be one reason for inadequate learning about aspects of NOS in the classrooms we studied.

\section{The contribution of the inquiry project}

Two aspects of NOS improved significantly, which we will now discuss. Biology students improved in understanding the interpretive nature of scientific knowledge. This improvement can be associated with the extended inquiry project which is a main requirement in biology. As biology teachers indicated, students need to explain their data and findings, a process that could lead to understanding that there are different ways to analyze data and explain findings. According to the teachers, the students are exposed to different interpretations of their group findings. These processes may contribute to understanding that the same findings can be interpreted in different ways and to the understanding that scientific knowledge is subjective.

The improvement of the biology students was limited to the aspect of understanding the interpretive nature of scientific knowledge. The limited improvement in other aspects was regardless of the teachers experience in conducting research, the teachers' good knowledge of NOS, and the substantial time devoted to the inquiry projects. We agree with those researchers who argue that implicit teaching of NOS while students are engaged in inquiry is not sufficient. The biology teachers described their involvement in the inquiry project with no reference to explicit teaching of NOS. Students conduct experiments, collect data, explain, and draw conclusions in a linear sequence. The teachers do not engage the students in discussions of various aspects of NOS when opportunities occur. Such implicit instruction does not leave room for

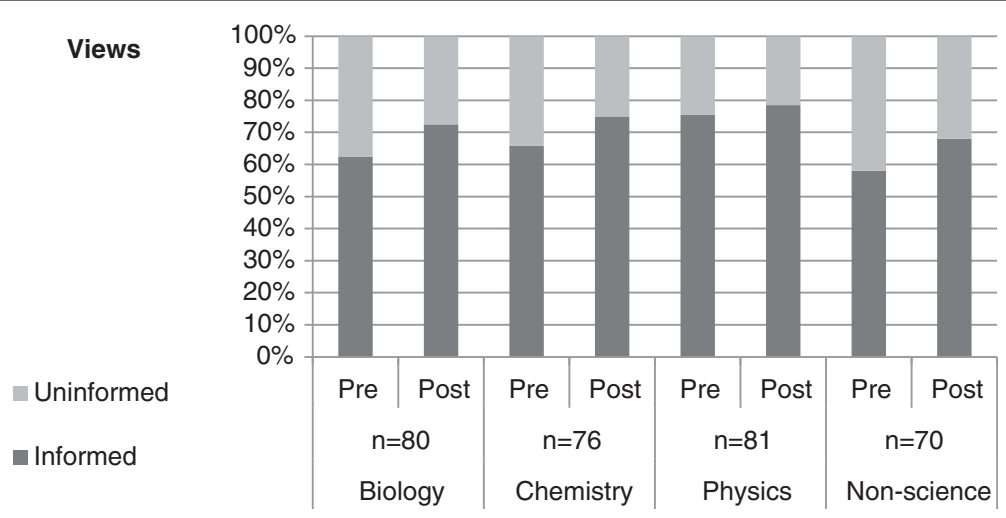

Figure 5 Understanding of social impacts on scientific research. 
reflection and thinking about the actions performed. In addition, it could be that although students understand that data and conclusions are important, they do not transfer this scientific thinking to extra-curricular contexts. It seems that non-explicit teaching, with no reflection and with no connection made between the practical work in school and real-world research, limited the potential of the inquiry project to improve the NOS understanding.

\section{The contribution of teaching the history of science}

Another aspect in which we found significant improvement was the understanding of the tentative nature of scientific knowledge among physics students. This improvement could be associated with the curriculum that deals with theoretical shifts in the twentieth century physics. This finding is in line with the literature that showed that teaching the history of science contributes to deeper understanding of NOS, at least in some areas (Irwin 2000; Lin and Chen 2002; Rudge et al. 2014; Solomon et al. 1992). Those studies claimed that historical cases have been especially effective in conveying the 'tentativeness' of science, as we found in our study. With historical perspective, students understand how, with additional evidence, scientists might outright reject former conclusions.

History is also a resource for learning about the cultural context of science. Students can follow how cultural ideas influenced science, by critical discussion of the type of research being funded, the types of questions that are asked, the theories that are developed, the filtering of observations, and the possible biases. The insignificant improvement of the physics students in other aspects implies that physics teachers do not teach, or do not emphasize, these aspects of NOS.

\section{Conclusions}

We found only a limited improvement in students' understanding of NOS after 2 years of enrollment in advanced placement courses in science. The limited improvement of students with high academic achievements implies that teachers do not teach NOS at all, or at least, do not emphasize aspects of NOS.

This research highlights the importance of making the NOS explicit: even though students were actively engaged in scientific inquiry, and studied the history of science, they did not get many of the key aspects of NOS. Many studies have shown already that implicit instruction is not effective in the development of NOS understanding. This study adds to that literature by showing that implicit instruction is not effective even when the intervention is an advanced 2-year science program and even with highly capable students and teachers.

We suggest that science teachers should adopt NOS as 'must-teach' content, not merely as a by-product of the inquiry process or historical illustrations. Fostering explicit instruction does not require reorganizing the entire curriculum. Teaching about the NOS does not have to take lots of 'extra' time but can be accomplished in the context of science topics that are already taught. The key is to take opportunities to strengthen these messages, ensure that they are accurate, and make them explicit. Highly contextualized activities are useful because teachers are less likely to view such activities as add-ons. This recommendation is also aligned with the association of NOS and teaching crosscutting concepts in the NRC K-12 framework and in the Next Generation Science Standards (REFS).

Simply including NOS in the science curricula does not guarantee that science teachers will teach it. If this highly important part of science is absent in the most important exams, one cannot expect to find the development of students' understanding. If teachers are to adopt a more positive approach to teaching NOS, we consider a real change in the current nature of the matriculation exams. The inclusion of NOS instruction in the various curricula should be more explicit. The curriculum should support teachers by providing relevant topics and contexts for teaching NOS, specific ideas, examples and suggestions for student activities, and above all good alignment between teaching and testing.

\section{Discussing possible limitations}

To increase the reliability of a test, it is recommended to build a test with a large number of questions and to examine each subject using a number of questions. However, we provided the students with two articles on climate change and eight open-ended questions to assess their NOS understanding. The Chief Scientist of the Ministry of Education who has to approve any research in the K-12 system allowed only one class period for administering the questionnaire. Following the pilot study, we reduced the number of questions to eight to fit a 45-min class in spite of possible negative impact on the instrument's reliability. On the other hand, longer instrument could undermine the validity as well due to students' fatigue.

Another possible limitation of the study is that the teachers' data were self-reported. What teachers say they do and what they actually do could differ significantly. With this respect, since there is no specific topic 'NOS', we could not schedule classroom observations. However, if the teachers would have given positive answers about their NOS teaching, we should have been more doubtful than we were given the teachers' honest (negative) answers about teaching NOS.

\section{Competing interests}

The authors declare that they have no competing interests.

\section{Authors' contributions}

OK carried out the research in schools. TT was her supervisor. They discussed, collected, and analyzed the data, and determined together the inter-rater 
reliability. They discussed discrepancy and wrote the paper together, with OK as the leading author. Both authors read and approved the final manuscript.

Received: 11 June 2014 Accepted: 15 November 2014 Published online: 09 December 2014

\section{References}

Abd-El-Khalick, F. (2005). Developing deeper understandings of nature of science: the impact of a philosophy of science course on preservice teachers' views and instructional planning. International Journal of Science Education, $27(1), 15-42$.

Abd-El-Khalick, F. (2012). Examining the sources for our understandings about science: enduring conflations and critical issues in research on nature of science in science education. International Journal of Science Education, 34(3), 353-374.

Abd-El-Khalick, F, \& Lederman, NG. (2000a). Improving science teachers' conceptions of nature of science: a critical review of the literature. International Journal of Science Education, 22(7), 665-701.

Abd-El-Khalick, F, \& Lederman, NG. (2000b). The influence of history of science courses on students' views on nature of science. Journal of Research in Science Teaching, 37(10), 1057-1059.

Abd-El-Khalick, F, Bell, RL, \& Lederman, NG. (1998). The nature of science and instructional practice: making the unnatural natural. Science Education, 82, $417-436$.

Akerson, VL, \& Hanuscin, DL. (2007). Teaching nature of science through inquiry: the results of a three-year professional development program. Journal of Research in Science Teaching, 44, 653-680.

Akerson, VL, \& Volrich, ML. (2006). Teaching nature of science explicitly in a first-grade internship setting. Journal of Research in Science Teaching, 43(4), 377-394.

Allchin, D. (2011). Evaluating knowledge of the nature of (whole) science. Science Education, 95, 918-942.

Allchin, D. (2014). From science studies to scientific literacy: a view from the classroom. Science \& Education, 23(9), 1911-1932.

Aydeniz, M, Baksa, K, \& Skinner, J. (2011). Understanding the impact of an apprenticeship-based authentic scientific research program on high school students' understanding of scientific inquiry. Journal of Science Education and Technology, 20(4), 403-421.

Bell, RL. (2007). Teaching the Nature of Science through Process Skills: Activities for Grades 3-8. New York: Allyn \& Bacon/Longman.

Bell, RL, Lederman, NG, \& Abd-El-Khalick, F. (1998). Implicit versus explicit nature of science instruction: an explicit response to Palmquist and Finley. Journal of Research in Science Teaching, 35(9), 1057-1061.

Bell, RL, Blair, LM, Crawford, BA, \& Lederman, NG. (2003). Just do it? Impact of a science apprenticeship program on high school students' understanding of the nature of science and scientific inquiry. Journal of Research in Science Teaching, 40(5), 487-509.

Bell, RL, Matkins, JJ, \& Gansneder, BM. (2011). Impacts of contextual and explicit instruction on preservice elementary teachers' understandings of the nature of science. Journal of Research in Science Teaching, 48(4), 414-436.

Clough, MP. (2006). Learners' responses to the demands of conceptual change: considerations for effective nature of science instruction. Science \& Education, 15(5), 463-494

Crawford, B. (2012). Moving the essence of inquiry into the classroom: Engaging teachers and students in authentic research. In KCD Tan \& M Kim (Eds.) Issues and challenges in science education research: Moving forward (pp. 25-42). Dordrecht: Springer.

Dogan, N, \& Abd-El-Khalick, F. (2008). Turkish grade 10 students' and science teachers' conceptions of nature of science: a national study. Journal of Research in Science Teaching, 45(10), 1083-1112.

Duschl, RA. (2000). Making the nature of science explicit. In R Millar, J Leach, \& J Osborne (Eds.), Improving science education: The contribution of research (pp. 187-206). Buckingham: Open University Press.

Duschl, RA, \& Grandy, RE. (2008). Teaching Scientific Inquiry: Recommendations for Research and Implementation. Rotterdam: Sense.

Eastwood, JL, Sadler, TD, Zeidler, DL, Lewis, A, Amiri, L, \& Applebaum, S. (2012). Contextualizing nature of science instruction in socioscientific issues. International Journal of Science Education, 34(15), 2289-2315.

Eflin, JT, Glennan, S, \& Reisch, G. (1999). The nature of science: a perspective from the philosophy of science. Journal of Research in Science Teaching, $36(1), 107-117$
Irwin, AR. (2000). Historical case studies: teaching the nature of science in context. Science Education, 84(1), 5-26.

Israel Ministry of Education (2010). Physics curriculum for high schools (in Hebrew). http://cms.education.gov.l/EducationCMS/Units/Tochniyot_Limudim/Physics/. Accessed 5 Dec 2014.

Israel Ministry of Education (2011a). Biology curriculum for high schools (in Hebrew). http://cms.education.gov.l//educationcms/units/tochniyot_limudim/biologic/ mavo/mavo.htm. Accessed 5 Dec 2014.

Israel Ministry of Education (2011b). Chemistry curriculum for high schools (in Hebrew). http://cms.education.gov.l/EducationCMS/Units/Mazkirut_Pedagogit/Chimya/ ThochniyotLimudimChadasha/TochnitLimudim.htm. Accessed 5 Dec 2014.

Johnson, RB, \& Onwuegbuzie, AJ. (2004). Mixed methods research: a research paradigm whose time has come. Educational Researcher, 33(7), 14-26.

Khishfe, R. (2012). Nature of science and decision-making. International Journal of Science Education, 34(1), 67-100

Khishfe, R, \& Abd-El-Khalick, F. (2002). Influence of explicit and reflective versus implicit inquiry-oriented instruction on sixth graders' views of nature of science. Journal of Research in Science Teaching, 39(7), 551-578.

Khishfe, R, \& Lederman, NG. (2006). Teaching nature of science within a controversial topic: integrated versus nonintegrated. Journal of Research in Science Teaching, 43(4), 395-418.

Khishfe, R, \& Lederman, NG. (2007). Relationship between instructional context and views of nature of science. International Journal of Science Education, 29(8), 939-961.

Koksal, MS, Cakiroglu, J, \& Geban, O. (2013). The effect of explicit embedded reflective instruction on nature of science understandings in advanced science students. Journal of Biological Education, 47(4), 208-223.

Krippendorff, K. (2004). Content Analysis: An introduction to its Methodology. Thousand Oaks: Sage.

Lederman, NG. (1992). Students' and teachers' conceptions of the nature of science: a review of the research. Journal of Research in Science Teaching, 29(4), 331-359.

Lederman, NG. (2007). Nature of science: Past, present and future. In SK Abell \& NG Lederman (Eds.), Handbook of research on science education (pp. 831-879). Mahwah: Lawrence Erlbaum.

Lederman, NG, \& O'Malley, M. (1990). Students' perceptions of tentativeness in science: development, use and sources of change. Science Education, 74(2), 225-239.

Lederman, NG, Abd-El-Khalik, F, Bell, RL, \& Schwartz, RS. (2002). Views of nature of science questionnaire: toward valid and meaningful assessment of learners' conceptions of nature of science. Journal of Research in Science Teaching, 39(6), 497-521

Lewis, A, Amiri, L, \& Sadler, T. (2006). Nature of Science in the Context of Socioscientific Issues (Paper presented at the National Association of Research in Science Teaching). San Francisco: CA, USA.

Lin, H, \& Chen, C. (2002). Promoting preservice chemistry teachers' understanding about the nature of science through history. Journal of Research in Science Teaching, 39(9), 773-792.

McComas, WF, Clough, MP, \& Almazroa, H. (1998). The role and character of the nature of science in science education. In WF McComas (Ed.), The nature of science in science education: Rationales and strategies (pp. 3-40). Hingham: Kluwer.

Meichtry, Y. (1992). Influencing students understanding of the nature of science: data from a case of curriculum development. Journal of Research in Science Teaching, 29(4), 389-407.

Morgan, DL. (2007). Paradigms lost and pragmatism regained: methodological implications of combining qualitative and quantitative methods. Journal of Mixed Methods Research, 1(1), 48-76.

NRC (National Research Council). (2012). A Framework for K-12 Science Education: Practices, Cross-Cutting Concepts and Core Ideas. Washington, DC: National Academies Press.

Osborne, J, Collins, S, Ratcliffe, M, Millar, R, \& Duschl, R. (2003). What "ideas-aboutscience" should be taught in school science? A Delphi study of the expert community. Journal of Research in Science Teaching, 40(7), 692-720.

Rudge, DW, Cassidy, DP, Fulford, JM, \& Howe, EM. (2014). Changes observed in views of the nature of science during a historically based unit. Science \& Education, 23(9), 1879-1909.

Sadler, TD, Chambers, FW, \& Zeidler, DL. (2004). Student conceptualizations of the nature of science in response to a socioscientific issue. International Journal of Science Education, 26(4), 387-409.

Sadler, TS, Burgin, S, McKinney, LL, \& Ponjuan, L. (2010). Learning science through research apprenticeships: a critical review of the literature. Journal of Research in Science Teaching, 47, 235-256. 
Sandoval, WA, \& Morrison, K. (2003). High school students' ideas about theories and theory change after a biological inquiry unit. Journal of Research in Science Teaching, 40(4), 369-392.

Schwartz, RS, Lederman, NG, \& Crawford, B. (2004). Developing views of nature of science in an authentic context: an explicit approach to bridging the gap between nature of science and scientific inquiry. Science Education, 88(4), 610-645.

Smith, MU, Lederman, NG, Bell, RL, McComas, WF, \& Clough, MP. (1997). How great is the disagreement about the nature of science: a response to Alters. Journal of Research in Science Teaching, 34(10), 1101-1103.

Solomon, J, Duveen, J, Scot, L, \& McCarthy, S. (1992). Teaching about the nature of science through history: action research in the classroom. Journal of Research in Science Teaching, 29, 409-421.

Tal, T, \& Kedmi, Y. (2006). Teaching socioscientific issues: classroom culture and students' performances. Cultural Studies of Science Education, 1(4), 615-644.

Tal, T, Kali, Y, Magid, S, \& Madhok, JJ. (2011). Enhancing the authenticity of a web-based module for teaching simple inheritance. In TD Sadler (Ed.), Socio-scientific issues in the classroom (pp. 11-38). Netherlands: Springer.

Tamir, P. (1972). Understanding the process of science by students exposed to different science curricula in Israel. Journal of Research in Science Teaching, 9(3), 239-245.

Tamir, P. (1994). Israeli students' conceptions of science and views about the scientific enterprise. Research in Science \& Technological Education, 12(2), 99-116.

Wu, YT, \& Tsai, CC. (2011). High school students' informal reasoning regarding a socio-scientific issue, with relation to scientific epistemological beliefs and cognitive structures. International Journal of Science Education, 33(3), 371-400.

Yang, F. (2005). Student views concerning evidence and the expert in reasoning a socio-scientific issue and personal epistemology. Educational Studies, $31(1), 65-84$

Zeidler, DL, Walker, KA, Ackett, WA, \& Simmons, ML. (2002). Tangled up in views: beliefs in the nature of science and responses to socioscientific dilemmas. Science Education, 86, 343-367.

doi:10.1186/s40594-014-0013-5

Cite this article as: Kahana and Tal: Understanding of high-achieving science students on the nature of science. International Journal of STEM Education 2014 1:13.

\section{Submit your manuscript to a SpringerOpen ${ }^{\circ}$ journal and benefit from:}

- Convenient online submission

- Rigorous peer review

- Immediate publication on acceptance

- Open access: articles freely available online

- High visibility within the field

- Retaining the copyright to your article

Submit your next manuscript at $\gg$ springeropen.com 